\title{
Archivo de Arquitectura Mexicana del Instituto de Investigaciones Estéticas
}

$\mathrm{E}$ l Archivo de Arquitectura Mexicana surgió ante la necesidad de encontrar nuevas líneas de investigación en torno a la historia y la crítica de la arquitectura de México. El Seminario de Arquitectura Moderna, coordinado por Enrique X. de Anda Alanís, al reconocer la importancia y urgencia de salvar los documentos históricos que contienen información acerca de importantes proyectos arquitectónicos y urbanísticos de México, creó el Archivo de Arquitectura Mexicana del Instituto de Investigaciones Estéticas (IIE) de la Universidad Nacional Autónoma de México (UNAM). El archivo empezó a partir de enero de 2006 con la donación y entrega en comodato al IIE de documentos y bibliotecas personales por parte de los herederos de los arquitectos cuyo nombre es homónimo al de los fondos que resguarda. A la fecha se sigue solicitando a distintos herederos la donación de archivos sobre arquitectura.

\section{Los fondos del Archivo de Arquitectura Mexicana}

\section{Fondo Domingo García Ramos}

Este archivo fue donado a la UNAM en enero de 2006 y contiene los documentos y la biblioteca personal que elaboró y conservó Domingo García Ramos desde I9I9 hasta 1978 (año de su muerte). También hay documentos póstumos que guardan relación directa con el personaje. El archivo de Domingo García 
Ramos se encontraba ubicado en la ciudad de México, en su estudio de trabajo situado en la casa que habitaban él y su familia. Desde el momento de su muerte, el estudio se conservó casi intacto. La familia tuvo interés en conservar su obra, no sólo por el lazo sentimental que los unía con los documentos, sino también por su importancia académica. Con el paso del tiempo, la familia de Domingo García Ramos fue creciendo y también cambiaron los intereses y perspectivas de cada uno de los miembros. Debido a cuestiones de espacio, la señora María Eugenia García, hija del arquitecto García Ramos, decidió donar a la UNAM —institución donde su padre se había formado y a la cual dedicó muchos años de su vida - los documentos personales del arquitecto (fig. I).

Este acervo está compuesto por una planoteca, un archivo documental (registros desde la educación primaria hasta su vida profesional), una fototeca con imágenes impresas y una biblioteca.

\section{Fondo Enrique Guerrero Larrañaga}

Enrique Guerrero Larrañaga donó personalmente a la UNAM en marzo de 2007 los documentos que hacen referencia a sus actividades académicas y profesionales. Este acervo documental fue seleccionado previamente por el autor y contiene unos Ioo expedientes documentales, entre los que se incluyen traducciones y publicaciones que él elaboró (fig. 2). El archivo documental consta de 55 expedientes con 200 documentos relativos a vida cotidiana, actividades profesionales y actividades académicas.

\section{Fondo José Luis Cuevas Pietrasanta}

La biblioteca de José Luis Cuevas Pietrasanta fue donada en septiembre de 2008 por los legatarios del arquitecto. Contiene 158 títulos relativos a temas de arquitectura y urbanismo. Cabe mencionar que la donación constó exclusivamente de los libros relacionados con la materia; el resto de la biblioteca sigue en posesión de los legatarios (fig. 3).

\section{Fondo Juan Segura Gutiérrez}

Esta planoteca contiene 224 planos de proyectos de los edificios para la fundación Mier y Pesado (fig. 4). 


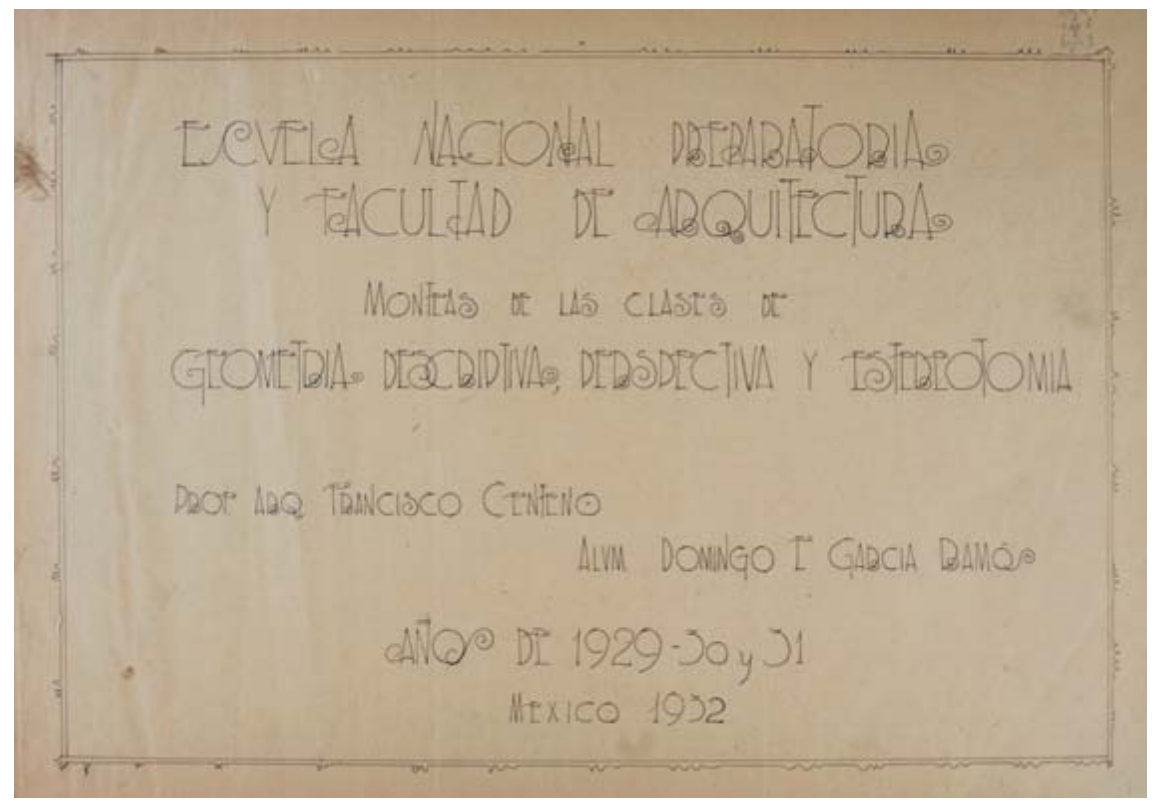

I. Domingo E. García Ramos, Monteas de las clases de geometría descriptiva, perspectiva y estereotomía, años de 1929-30 y 31, México, 1932, Archivo de Arquitectura Mexicana-Fondo Domingo García Ramos, sección I, serie I.3, exp. 9, doc. I.

Fondo de Diapositivas Nezahualcóyotl Gómez

El acervo está formado por 900 diapositivas de obras de arquitectura moderna de la ciudad de México, tomadas en la década de 1980 por el fotógrafo Nezahualcóyotl Gómez. El fondo se compone de II secciones concernientes a imágenes de conjuntos arquitectónicos de la ciudad de México, entre las que destaca la sección Luis Barragán con cerca de 200 diapositivas (fig. 5).

\section{Fondo de Tarjetas Postales}

La creación del Fondo de Tarjetas Postales fue reconocida por el Fondo Nacional para la Cultura y las Artes (Fonca) a través del Programa de Fomento y Coinversiones Culturales, mismo que patrocina el proyecto Imaginario y Tarjetas Postales en la Cultura Urbana de México durante el Siglo xx: Creación del Archivo, Metodología, Sistema de Consulta y Estudio Iconográfico (fig. 6). 


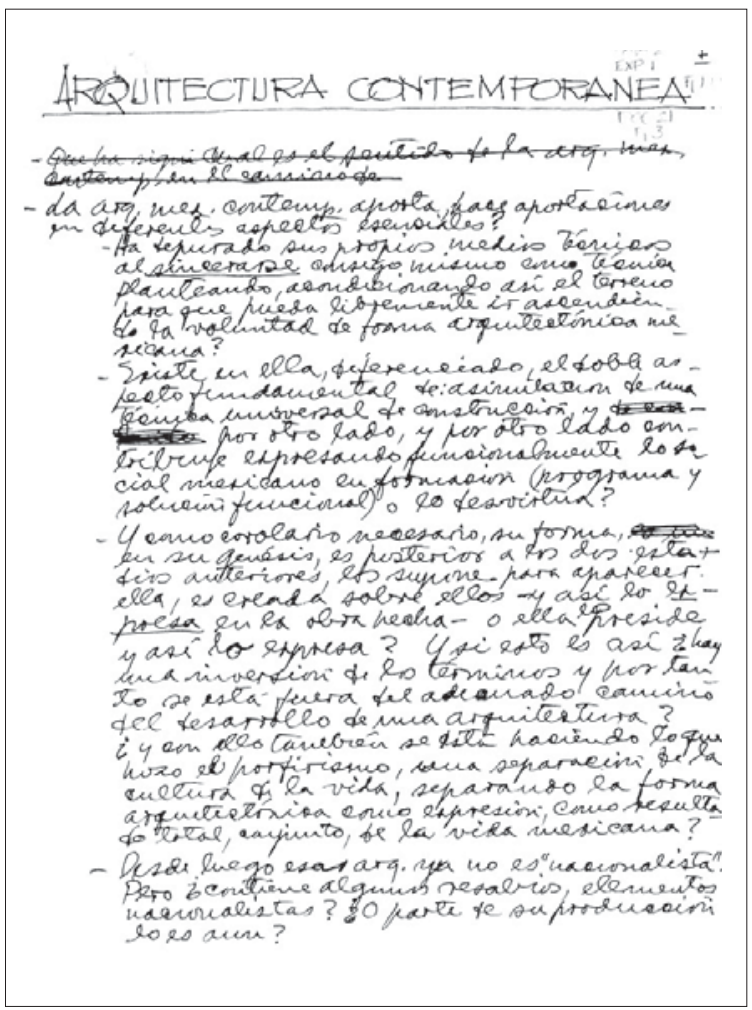

2. Enrique Guerrero Larrañaga, Notas manuscritas sobre arquitectura contemporánea [1950], Archivo de Arquitectura Mexicana-Fondo Enrique Guerrero Larrañaga, sección 3, serie 3.4, subserie 3.4.2, exp.I, doc. $2 \mathrm{I}$.

A partir de diciembre de 2009, la colección de tarjetas postales y las transparencias han sido donadas por la comunidad universitaria interesada en resguardar y coadyuvar a la preservación de la memoria de la cultura arquitectónica mexicana. Este acervo cuenta con 600 piezas cuyos temas abarcan paisajes arquitectónicos mexicanos desde el siglo Iv hasta mediados del xx, para consulta del público y estudio iconográfico.

\section{Fondo de Audio}

En este espacio se guardan entrevistas de audio con arquitectos mexicanos del periodo moderno. 
3. Theodora Kimball, Manual of Information on City Planning and Zoning, 1923, Archivo

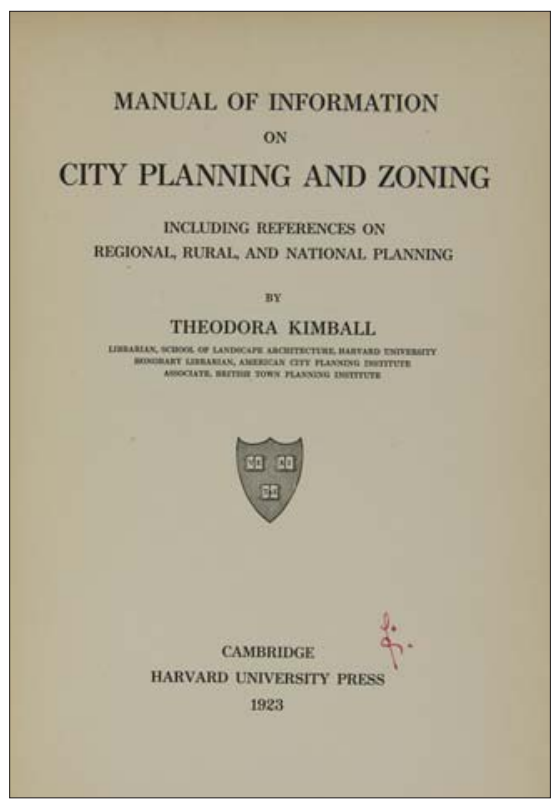
de Arquitectura Mexicana-Fondo José Luis Cuevas Pietrasanta.

Base de datos de las escuelas del CAPFCE

Esta base de datos es un derivado de la investigación iniciada por Enrique X. de Anda Alanís en diciembre de 2004 con el título "Arquitectura y proyecto escolar en México: 1944-1946". El proyecto supone una investigación histórica sobre las escuelas construidas en México en 1944, I945 y 1946, de acuerdo con el programa nacional que desarrolló el Comité Administrador del Programa Federal para la Construcción de Escuelas (CAPFCE) desde su fundación (Io de febrero de 1944) hasta el último día del mandato presidencial del general Manuel Ávila Camacho (30 de noviembre de 1946).

La base de datos contiene la catalogación de los objetos de estudio, así como comentarios generales del autor sobre asuntos significativos, con el propósito de ubicar la importancia de algunos casos.

El proyecto sigue en marcha: se trata de una tarea de localización, identificación y reflexión, que por el momento ofrece ya sus primeros resultados. ${ }^{\mathrm{I}}$

I. Enrique X. de Anda, "Presentación”, en Arquitectura escolar y proyecto de educación en México, 1944-1946 (base de datos), disco compacto, 2005. 
DOI: http://dx.doi.org/10.22201/iie.18703062e.2010.97.2315

I 50 SABRINA BAÑOS POO

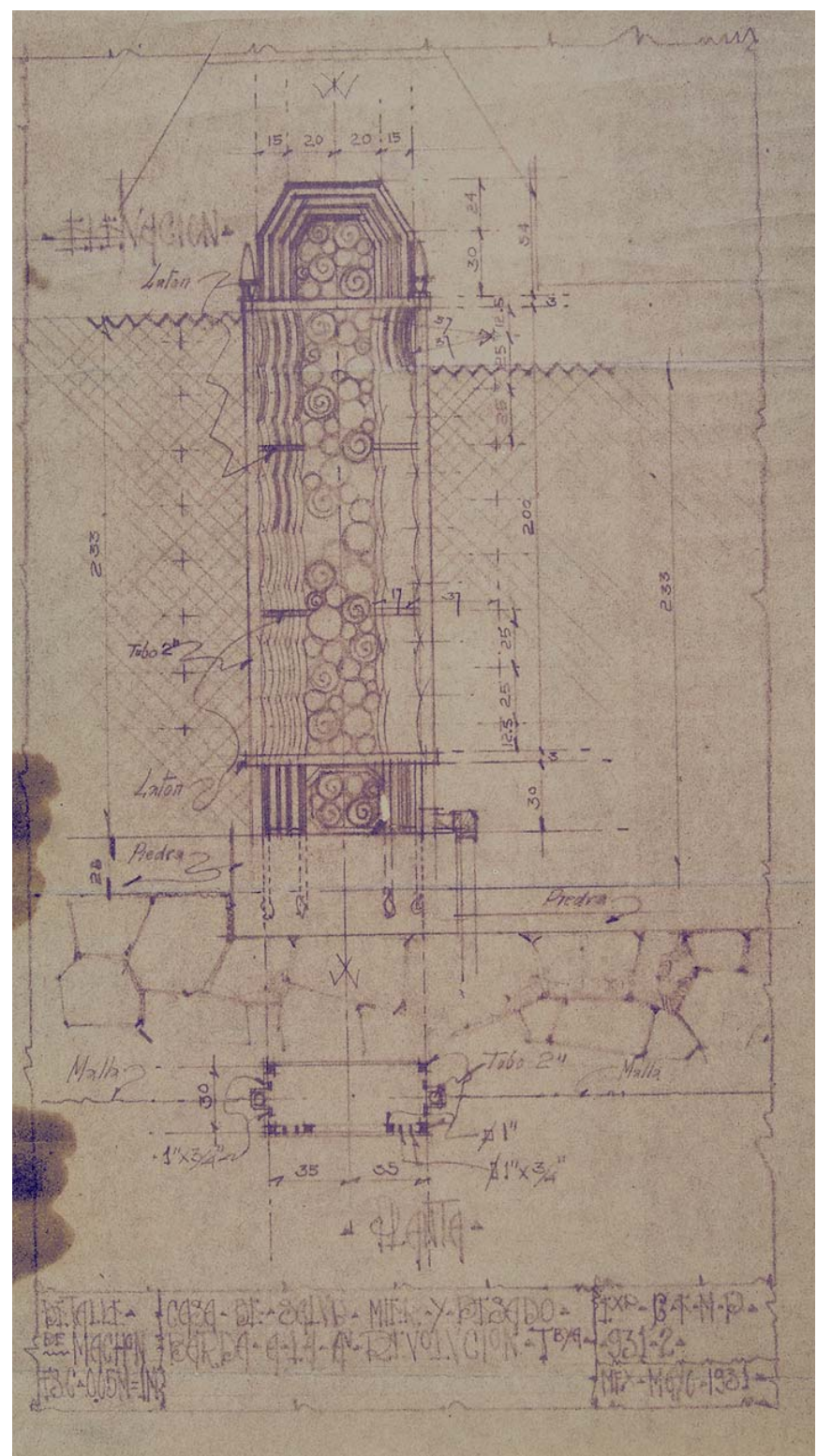

4. Juan Segura Gutiérrez, detalle de la Casa de salud Mier y Pesado, I93 I, Archivo de Arquitectura Mexicana-Fondo Juan Segura Gutiérrez. 


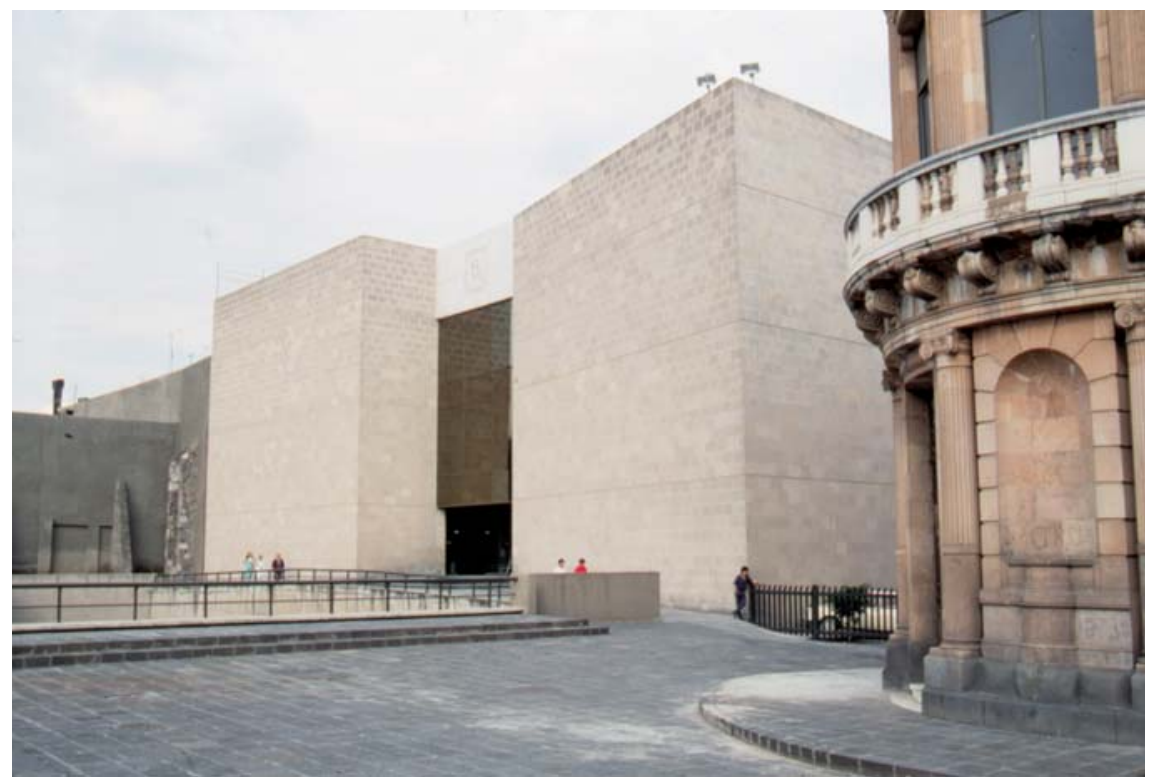

5. Nezahualcóyotl Gómez, Templo mayor, ca. 1980, Archivo de Arquitectura MexicanaFondo Nezahualcóyotl Gómez, sección 3, serie 3.2, subserie 3.2.3. Conaculta-INAH-Méx. Reproducción autorizada por el Instituto Nacional de Antropología e Historia.

\section{Trabajo académico y descripción del Archivo de Arquitectura Mexicana}

La organización, clasificación y catalogación del Archivo de Arquitectura Mexicana se ha llevado a cabo bajo los estándares de la Norma Internacional General de Descripción Archivística (ISAD-G por sus siglas en inglés, General International Standard Archives Description) impulsada por el Consejo Internacional de Archivos desde 1998. Esta norma contiene reglas generales para la descripción archivística que pueden aplicarse independientemente del tipo documental o del soporte físico de los documentos de archivo. La ISAD-G es el conjunto de reglas que tiene como fin garantizar la elaboración de descripciones vinculadas directamente con los originales — dicho en otras palabras, que sean coherentes y útiles para el usuario-; facilitar la recuperación y el 
intercambio de información de los documentos de un archivo - esto quiere decir que la ISAD-G demanda la conservación de los originales, pero además la propagación de su contenido a través de la información que el archivista pueda generar al catalogar o describir cada una de las piezas documentales-; compartir los datos de autoridad — esto es, informar al público sobre la historia o biografía de la institución o personaje que creó la documentación del fondo en cuestión-; hacer posible la integración de las descripciones procedentes de distintos lugares en un sistema unificado de información - lo que significa que no es necesario concentrar los originales en el mismo lugar; es posible elaborar catálogos descriptivos con imágenes digitalizadas, logrando ejecutar archivos virtuales con políticas específicas de acceso y reproducción. Este punto se refiere también a la posibilidad de generar ligas de intercambio de información entre varios acervos.

Para el cumplimiento de estos objetivos, las reglas identifican y definen 26 elementos que pueden combinarse entre sí para constituir la descripción de una entidad archivística. A fin de lograr lo anterior, la norma se estructura en siete áreas de información que van a orientar al usuario sobre el estado del documento, el momento en que se creó, el contexto actual del original y el modo como se puede tener acceso a estas fuentes (es importante mencionar que cada pieza es una unidad de descripción):

- El área de identificación: proporciona la información esencial para identificar la unidad de descripción en las herramientas descriptivas del archivo.

- El área de contexto: contiene los datos relativos al origen y la custodia de la unidad de descripción.

- El área de contenido y estructura: posee información referente al objeto y la organización de la unidad de descripción.

- El área de acceso y utilización: incluye información acerca de la accesibilidad del documento.

- El área de documentación asociada: informa de los documentos que tienen una relación significativa con la unidad de descripción.

- El área de notas: proporciona información especial que no ha podido incluirse en otras áreas.

- El área del control de la descripción: contiene información relativa a cómo y cuándo se ha elaborado la descripción archivística y quién la ha preparado. 


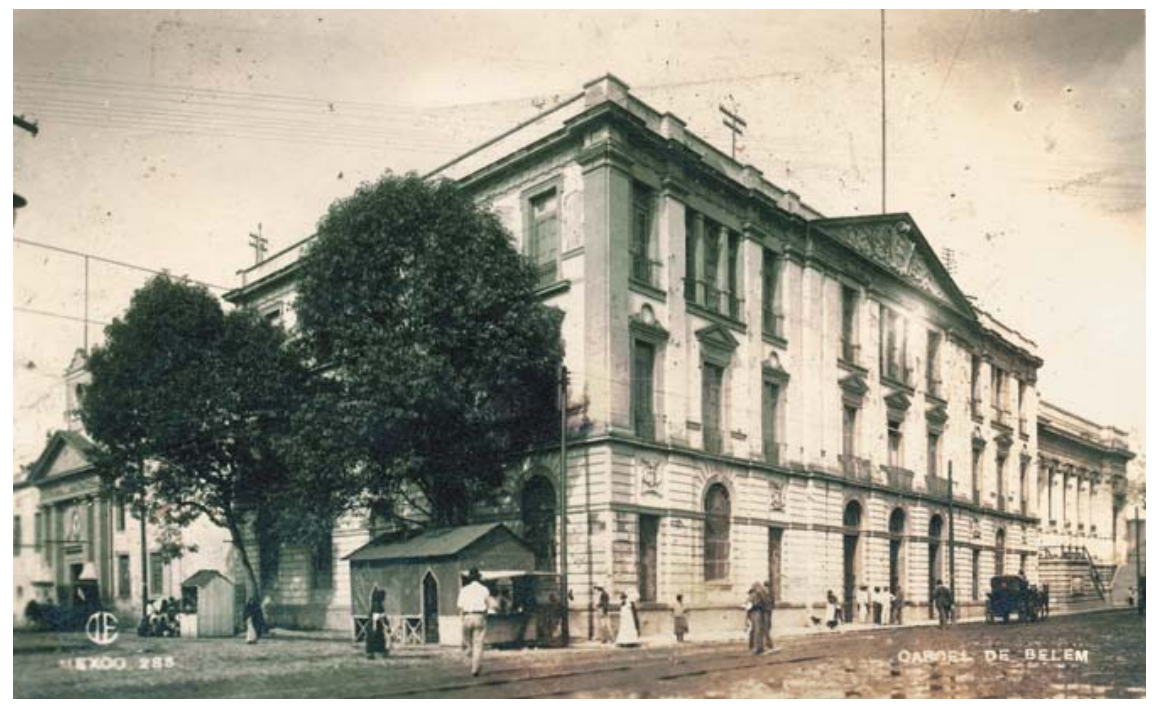

6. Mexfoto color (MF), México, Cárcel de Belem, s.f., Archivo de Arquitectura MexicanaFondo de Tarjetas Postales, sección 6, exp. 2, doc. 17.

\section{Difusión del Archivo de Arquitectura Mexicana}

Este archivo se difundirá por medio de un sistema de consulta informático vía red. La comunidad académica podrá ingresar al catálogo a través del sistema. Éste ofrecerá, además del catálogo del archivo, información complementaria por medio de una guía general y un inventario según la norma ISAD-G. El material quedará disponible a los interesados en el portal www.arqmoderna. esteticas.unam.mx, que forma parte de la sección de seminarios de la página electrónica del Instituto de Investigaciones Estéticas de la UNAM. Los materiales originales seguirán bajo la custodia del IIE y solamente podrán consultarse en casos especiales.

\section{Grupo de trabajo del Archivo de Arquitectura Mexicana}

El proyecto del Archivo de Arquitectura Mexicana del IIE cuenta con un equipo de investigación, conformado por académicos y alumnos interesados en la cultura arquitectónica, y con el apoyo profesional de especialistas del 
IIE en diversas disciplinas afines: Ricardo Alvarado, Pedro Ángeles, Rómulo Enrique Cartas, Tania Ixchel Pérez, Mariana Planck, Columba Sánchez, María del Carmen Sifuentes, Gerardo Vázquez, José Antonio Villarreal.

\section{Reconocimientos}

El equipo de investigación se ha dedicado a la organización, preservación, digitalización y puesta en servicio del archivo. El proyecto cuenta con el reconocimiento de la Dirección General de Asuntos del Personal Académico de la UnAM, a través del Programa de Apoyo a Proyectos para la Innovación y Mejoramiento de la Enseñanza, desde enero de 2009; la Asociación de Apoyo al Desarrollo de Archivos y Bibliotecas de México (Adabi de México), desde enero de 2009, y del Fondo Nacional para la Cultura y las Artes (Fonca), a través del Programa de Fomento y Coinversiones Culturales, desde enero de 20I0. A la fecha se sigue solicitando a distintos herederos la donación de archivos sobre arquitectura.

\section{Espacios con que cuenta el archivo}

Actualmente, el Archivo de Arquitectura Mexicana tiene un espacio de fondo reservado, un área de trabajo y otra de cómputo. El área de consulta estará ubicada en la Biblioteca Justino Fernández del Instituto de Investigaciones Estéticas.

\section{Proyectos asociados}

El Fonca, a través del Programa de Fomento y Coinversiones Culturales, patrocina el proyecto Imaginario y Tarjetas Postales en la Cultura Urbana de México durante el Siglo xx: Creación del Archivo, Metodología, Sistema de Consulta y Estudio Iconográfico (clave del proyecto 885.C.or. EC.007.09 [25]).

La Dirección General de Asuntos del Personal Académico de la unam, a través del Programa de Apoyo a Proyectos para la Innovación y Mejoramiento de la Enseñanza, patrocina el proyecto Investigación en Archivo Documen- 
tal: Técnicas de Organización y Trabajo para Estudiantes; Preparación de un Manual de Apoyo para Lectura de Imágenes y Difusión del Contenido del Archivo Arquitecto Domingo García Ramos (clave PE401309). El resultado del primer año de trabajo es un manual dirigido a los estudiantes de licenciatura, con el fin de que tengan un acercamiento a los archivos históricos. El Manual de técnicas. Investigación en archivo documental ${ }^{2}$ pretende dar a conocer el funcionamiento y las herramientas básicas de un archivo. Las ideas del contenido del manual surgieron de las experiencias del grupo de trabajo compuesto por becarios y académicos profesionales de la materia archivística. En este segundo año de trabajo, el manual se enfocará al uso de las imágenes como documentos de estudio. La Adabi de México patrocina desde 2009 el proyecto Catalogación, Preservación y Puesta en Servicio del Archivo de Arquitectura Mexicana (clave DFos-APBB-IoD). \$े

2. Sabrina Baños Poo, Manual de técnicas. Investigación en archivo documental, México, Universidad Nacional Autónoma de México-Dirección General de Asuntos del Personal Académico, 20 Io. 